\title{
Structural and Surface Morphology Transformation of Plant Assisted Silver Nanoparticles and Its Biological Applications
}

\author{
P. Jamila Jayanthi ${ }^{1, *}$, I. Kartharinal Punithavathy' ${ }^{1}$, S. Johnson Jeyakumar ${ }^{1}$, T. Elavazhagan ${ }^{2}$ \\ ${ }^{1} P G$ \& Research Department of Physics, T.B.M.L College, Porayar - 609307, Tamilnadu, India. \\ ${ }^{2}$ Department of Biotechnology, Research and Development Centre, Bharathiyar University, Coimbatore - 641 046, Tamilnadu, India.
}

\section{ARTICLE DETAILS}

\section{Article history:}

Received 05 February 2019

Accepted 18 February 2019

Available online 25 March 2019

\section{Keywords:}

Nanosilver

Tridax procumbens

Antibacterial Efficacy

\begin{abstract}
A B S T R A C T
The preparation, optimization and application of biogenic nanomaterials have become the major division of study in nanotechnology. This study reports the single step; eco-friendly synthesis of silver nanoparticles using the aqueous extract of Tridax procumbens plant extracts with different extract concentrations $(10 \mathrm{~mL}$ to $40 \mathrm{~mL})$. The aqueous extract of Tridax procumbens showed significant potential for the fast reduction of silver ions without using any external agents. XRD pattern of Ag-NPs was indexed to face-centered cubic structure. The structural parameters of silver nanoparticles have been estimated and grain size ranged from $21 \mathrm{~nm}$ to $44 \mathrm{~nm}$. The UV-vis absorbance spectrum was observed at $424 \mathrm{~nm}$. The FT-IR analysis confirmed the secondary metabolites bind on surface of the AgNPs. SEM studies concluded morphological transformation of surface of the silver nanoparticles. Silver nanospheres were transformed in to rectangular silver nanosheets by increasing the extract concentration. Elemental silver formations were confirmed by EDAX studies. The antibacterial efficacies of synthesized nanosilver were carried out against different human bacterial pathogens and found to show significant activity. Bio-synthesis of Ag-NPs using Tridax procumbens appears to be cost effective, biodegradable and an alternative to conventional synthesis methods.
\end{abstract}

\section{Introduction}

The synthesis of nanoparticles is in the lime light in modern nanotechnology. The improvement of biologically inspired experimental processes for the synthesis of nanoparticles is evolving into an essential branch of nanotechnology [1]. At present, nanotechnology is a rapidly developing field of importance since it deals with the synthesis and stabilization of various metal nanoparticles. Among the nanoparticles, silver nanoparticles (Ag-NPs) have become the focus of intensive research due to several important applications such as their use in bio-labeling, sensors, drug delivery system, antimicrobial agents and filters. The synthesized silver nanoparticles exhibit new or improved properties depending upon their size, morphology and distribution [2-4].

Biological synthesis of nanoparticles is a relatively new emerging field of nanotechnology which has economic and eco-friendly benefits over chemical and physical processes of synthesis [5-7]. Conventional synthesis always takes more reaction time and also demands subsequent extraction and upturn steps. On the contrary, plant assisted synthesis always takes place extracellularly, and the reaction times have also been reported to be very short compared to that of microbial synthesis [8]. Moreover, green synthesis of different metallic nanoparticles using plant materials has successfully made an important contribution to green nanotechnology as it implements novel green chemistry approach with added advantages over chemical and physical methods: as it is environment-friendly, it does not need high pressure or high temperature, and toxic chemicals $[9,10]$.

Treatment of diseases with medicinal plants is more beneficial than synthetic and modern medicines as, ease of use, treatment efficacy, affordable cost and minimal side effects [11]. The plant Tridax procumbens is effective in treatment of wound healing, hypertension, bronchial catarrh, malaria, diarrhea, headache, liver disorders, obesity, jaundice, conjunctivitis and haemorrhage from skin injuries. The floral part has been reported for effective pharmaceutical properties such as antiseptic, insecticidal, parasiticidal and anti- hair falling thereby promoting its growth. Pharmacological activities in literature include immune- 


\subsection{Biosynthesis of Plant Mediated Ag-NPs}

Silver nitrate solution was prepared by adding $10 \mathrm{Mm}$ of $\mathrm{AgNO}_{3}$ into $20 \mathrm{~mL}$ distilled water. $10 \mathrm{~mL}$ of concentrated extract was added to $90 \mathrm{~mL}$ of deionized water with constant stirring at $60{ }^{\circ} \mathrm{C}$. $\mathrm{AgNO}_{3}$ solution was added drop wise into extract mixture. After the entire quantity of silver nitrate solution was added, the reaction mixture was stirred for $20 \mathrm{~min}$ with constant temperature. The colour changed from light yellow to dark brown. The brown precipitates were separated by centrifugation and washed with distilled water several times and isolate the pure Ag-NPs and exclude the presence of any unbound plant extract residue. The separated particles were incubated at $80^{\circ} \mathrm{C}$ until the moisture could be removed. The black colour highly crystallized silver nanoparticles were obtained. The same procedure was repeated for various concentrations such as $20 \mathrm{~mL}$, $30 \mathrm{~mL}$ and $40 \mathrm{~mL}$ of Tridax procumbens plant extract.

\subsection{Characterizations of the Nanoparticles}

The crystal structure and phase of silver nanoparticles were found by X-ray diffraction (SHIMADZU-XRD 6000) analysis. The morphology of the Ag nanoparticles was analyzed by scanning electron microscopy (Hitachi S-4500 SEM Machine). The absorption spectra were measured using UVVis spectrophotometer (SHIMADZU-UV 1800). Fourier transform infrared (FT-IR) spectra were recorded in the range $4000-500 \mathrm{~cm}^{-1}$ using a BRUKER: RFS 27.

\subsection{Determination of Antibacterial Activity by Disc Diffusion Method}

The test organisms were sub cultured using nutrient agar medium. The tubes containing sterilized medium were inoculated with the respective bacterial strain. After incubation at $37 \pm 1{ }^{\circ} \mathrm{C}$ for 18 hours, they were stored in a refrigerator. The nutrient agar medium was sterilized by autoclaving at $121{ }^{\circ} \mathrm{C}$ for $15 \mathrm{~min}$. The petriplates, tubes and flasks plugged with cotton were sterilized in hot-air oven at $160{ }^{\circ} \mathrm{C}$, for an hour. Into each sterilized petriplate $(20 \mathrm{~cm}$ diameter), was poured about $125 \mathrm{~mL}$ of molten nutrient agar medium which was already inoculated with the respective strain of bacteria (5 mL of inoculums to $250 \mathrm{~mL}$ of nutrient agar medium) aseptically. The plates were left at room temperature aseptically to allow solidification. After solidification, the paper discs containing the derivatives were placed at different areas on the surface of each plate and labelled accordingly.

Each test compound $(5 \mathrm{mg})$ was dissolved in dimethyl sulfoxide $(5 \mathrm{~mL}$ AR grade) to give a concentration of $1000 \mu \mathrm{g} / \mathrm{mL}$. Ciprofloxacin solution was also prepared to give a concentration of $1000 \mu \mathrm{g} / \mathrm{mL}$ in sterilized distilled water. The $\mathrm{pH}$ of all the test solutions and control were maintained in between 2 and 3 by using conc. $\mathrm{HCl}$. All the compounds were tested at dose levels of $1000 \mu \mathrm{g}$ and DMSO used as a control. The solutions of each test compound, control and reference standard were added separately in the cups and the plates were kept undisturbed for at least 2 hours in a refrigerator to allow diffusion of the solution properly into nutrient agar medium. Petri dishes were subsequently incubated at $37 \pm 1$ ${ }^{\circ} \mathrm{C}$ for 24 hours. After incubation, the diameter of zone of inhibition surrounding each of the cups was measured with the help of an antibiotic zone reader.

\section{Results and Discussion}

\subsection{Structural Analysis}

Fig. 1 shows the XRD patterns of Ag nanoparticles formed in different concentrations of plant extract which indicates in the formation of the crystalline nanostructures. The diffraction peaks in the XRD pattern of silver nanocrystal corresponding to the position 38.05 (1 11 1), 44.19 (2 0 0), $64.39\left(\begin{array}{lll}2 & 2 & 0\end{array}\right)$ and 77.31 (3 111 ) for Ag-NPs with different extract concentration. XRD patterns indexed to face-centered cubic structure of silver (JCPDS file No: 04-0783) [21-24]. The intensity of peaks reflects the high degree of crystallinity of the silver nanoparticles. When the concentration of plant extract increased from $10 \mathrm{~mL}$ to $20 \mathrm{~mL}$, the peak intensity also increased.

It is observed that the peak intensity increased with increase in extract concentration up to $20 \mathrm{~mL}$ and above that it decreases and the peak position shifted towards higher Bragg's angle (Fig. 2). This phase shift may cause fluctuation on the surface and volume contraction of the Ag-NPs. The increase of strain causes the increase in dislocation density and reduction in the crystal size Fig. 3.

All the XRD peaks showed that the main composition of nanoparticles was silver and clearly no undeniable other foreign peaks present as impurities in the XRD pattern therefore, the presence of secondary metabolites improves the stability of Ag-NPs and also prevents Ag-NPs from oxidation.

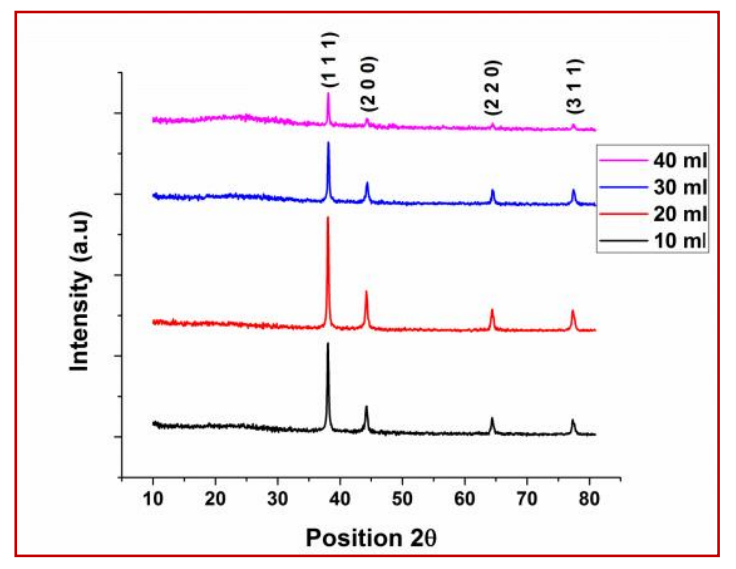

Fig. 1 XRD pattern Ag-NPs at various concentration of T. procumbens plant extract

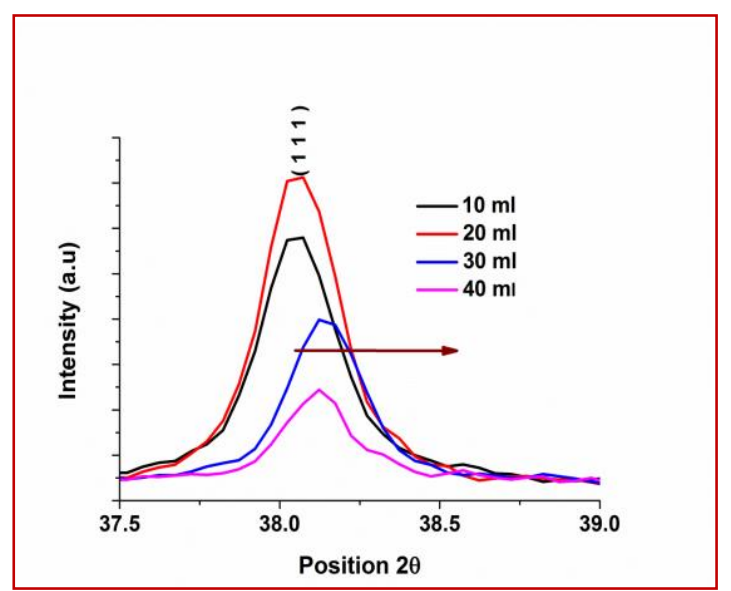

Fig. 2 Phase shift of dominant peak at different extract concentration

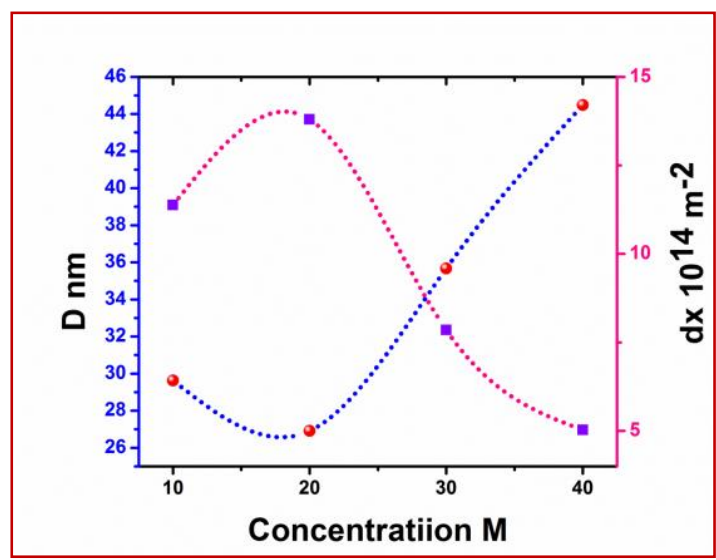

Fig. 3 Relation between crystallite size and dislocation density of Ag-NPs for various extract concentration

The crystallite size of the Ag-NPs was calculated from X-ray line broadening of the high intensity diffraction peaks of $\left(\begin{array}{lll}1 & 1 & 1\end{array}\right)$ plane using Debye Scherer's formula [25],

$$
\text { The crystallite size (D) }=\frac{0.94 \lambda}{\beta \cos \theta}
$$

where $\lambda$ is the wavelength of X-ray used (1.5406 $\AA$ ), $\beta$ is the angular peak width at half maximum in radian along ( $\left.\begin{array}{lll}1 & 1 & 1\end{array}\right)$ plane and $\theta$ is Bragg's diffraction angle. The optimum crystallite size was observed by extract concentration of $20 \mathrm{~mL}$. The micro-strain $(\varepsilon)$ [26], dislocation density $(\delta)$ [27] and stacking fault (SF) [28] were calculated using the relations:

$$
\begin{aligned}
& \varepsilon=\frac{\beta \cos \theta}{4} \\
& \delta=\frac{1}{\mathrm{D}^{2}} \\
& S F=\left[\frac{2 \pi^{2}}{45(3 \tan \theta)^{\frac{1}{2}}}\right] \beta
\end{aligned}
$$


The lattice parameters $(\mathrm{a}=\mathrm{b}=\mathrm{c})$ for the cubic phase are determined by the equation,

$$
d=\frac{\mathrm{a}}{\sqrt{h^{2}+k^{2}+l^{2}}}
$$

where $\mathrm{d}$ is the lattice spacing of the crystal planes (hkl).

The structural parameters such as dislocation density $(\delta)$, micro strain $(\varepsilon)$, and stacking fault (SF) of Ag-Nps were summarized in Table 1.

Table 1 Structural parameters of bio silver nanoparticles with different extract concentration

\begin{tabular}{lllllll}
\hline $\begin{array}{l}\text { Extract } \\
\begin{array}{l}\text { Concentration } \\
(\mathrm{mL})\end{array}\end{array}$ & $\begin{array}{l}\text { Crystallite } \\
\text { size }\end{array}$ & $\begin{array}{l}\text { Dislocation } \\
\text { density } \delta \mathrm{x}\end{array}$ & $\begin{array}{l}\text { Micro } \\
\text { strain }\end{array}$ & $\begin{array}{l}\text { Stacking } \\
\text { Fault }\end{array}$ & $\begin{array}{l}\text { Lattice } \\
\text { constant }\end{array}$ & $\begin{array}{l}\text { Volume } \\
\left(\mathrm{m}^{3}\right)\end{array}$ \\
\hline 10 & 29.63 & 11.38 & 0.0012 & 0.0022 & 4.0904 & 68.65 \\
20 & 21.15 & 20.37 & 0.0016 & 0.0024 & 4.0866 & 68.71 \\
30 & 35.67 & 7.85 & 0.0010 & 0.0018 & 4.0947 & 68.44 \\
40 & 44.48 & 5.03 & 0.0008 & 0.0014 & 4.0959 & 68.25 \\
\hline
\end{tabular}

The calculated lattice parameters were found to be $4.0904,4.0866$, and 4.0947 and $4.0959 \mathrm{~nm}$. As the extract concentration of T. procumbens increases, the value of lattice parameters observed to be decreases. It can be noticed that $20 \mathrm{~mL}$ has the optimized and favorable parameter rather than other concentrations and fair agreement with standard value for silver (4.0857 $\AA$ ) with an average crystal size of $21.15 \mathrm{~nm}$.

\subsection{Optical Analysis}

The absorbance spectra of the bio silver nanoparticles are shown in Fig. 4. Ag-NPs with $21.15 \mathrm{~nm}$ have a narrow band, which represents maximum at $424 \mathrm{~nm}$. It is reported that the SPR peak of spherical Ag-NPs attains maximum absorbance at $420 \mathrm{~nm}$ to $450 \mathrm{~nm}$.

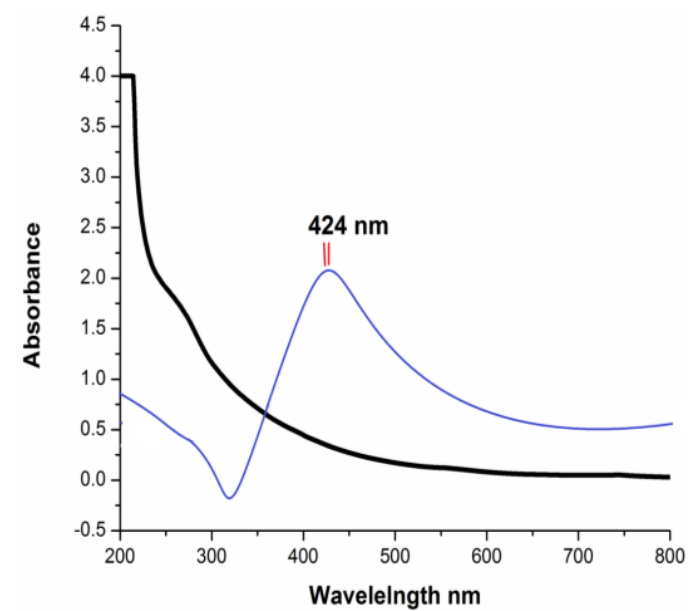

Fig. 4 UV absorption spectrum of (a) T. procumbens aqueous extract; and (b) $T$. procumbens mediated Ag-NPs

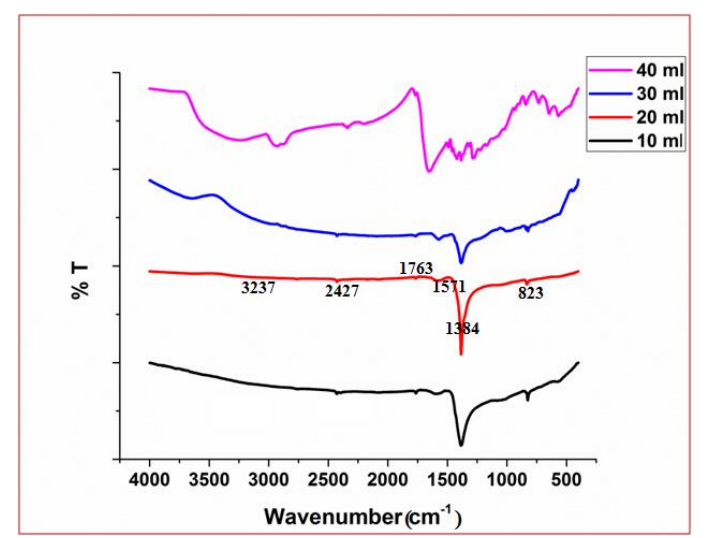

Fig. 5 FT-IR spectra for Ag-NPs for different extract concentration

\subsection{Functional Group Identification}

FTIR analysis was used to analyze the combination of biological molecules and composites in the synthesis of nanosilver to confirm the reduction and adsorption of chemical components in T. procumbens plant https://doi.org/10.30799/jnst.207.19050114 extract. The comprehensive study of the FTIR spectra suggested the presence of hydroxyl, amino, amide and carbonyl groups in the plant extract which might be responsible for the reduction and capping effect of the silver nanoparticles. The strong bands assigned to the adsorbed proteins are observed at $1384 \mathrm{~cm}^{-1}$ and $1768 \mathrm{~cm}^{-1}$ assigned to the amide III and amide I modes, respectively. The amide functional group consists of a carbonyl group bonded to nitrogen. Absorptions in $1384 \mathrm{~cm}^{-1}$ was caused by C-N stretching vibration of the aromatic amino groups [10].

Secondary metabolites promote the nucleation of Ag-NPs and also effectively stabilizes disperse silver nanoparticles. The bands at 823-832 $\mathrm{cm}^{-1}$ were characterization of out of plane deformation vibrations of $\mathrm{C}-\mathrm{H}$ groups in aromatic structures.

Table 2 Vibrational assignments for plant mediated Ag-NPs

\begin{tabular}{ll}
\hline Observed Wave number $\mathrm{cm}^{-1}$ & Vibrational assignments \\
\hline $3237-3640$ & O-H Stretching \\
$2427-2338$ & $\mathrm{C}-\mathrm{N}$ asymmetric Stretching \\
$1763-1768$ & $\mathrm{C}=\mathrm{O}$ stretching \\
$1571-1592$ & $\mathrm{NO}_{2}$ asymmetric stretching \\
1384 & $\mathrm{C}-\mathrm{N}$ stretching \\
$823-832$ & $\mathrm{C}-\mathrm{H}$ bending \\
\hline
\end{tabular}

\subsection{Elemental Analysis}

The strong signal of silver nanoparticles from EDAX spectrum confirms the chemical homogeneity of elemental silver nanoparticles. The high intensity spectrum indicates abundance of silver nanoparticles (Fig. 6). The appearance of $\mathrm{C}$ and $\mathrm{O}$ peaks were due to the mixture of bio molecules present on the surface of silver nanoparticles. No other impurity peaks detected. Therefore, the EDAX profile indicates the purity of Ag-NPs.

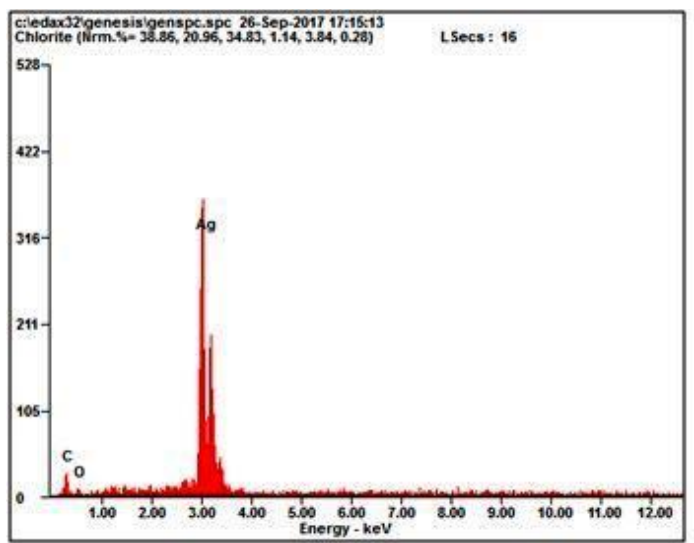

Fig. 6 EDAX Spectrum for silver nanoparticles

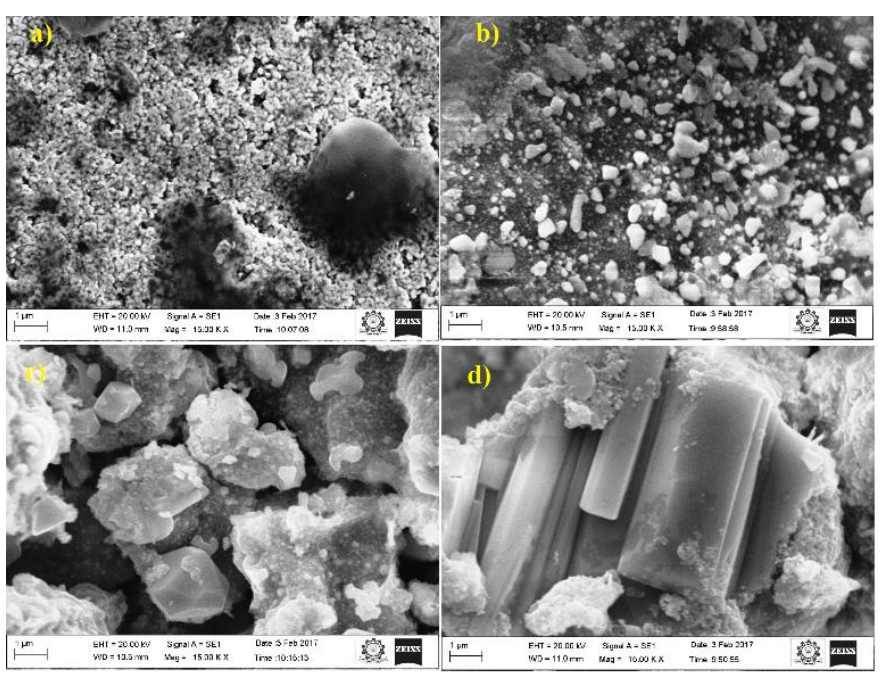

Fig. 7 Morphological transformation of synthesized Ag-NPs for various concentration of plant extract

\subsection{Surface Morphology}

The surface appearance of nanoparticles as SEM images were shown in Fig. 7a-d. When the extract concentration increases from $10 \mathrm{~mL}$ to $40 \mathrm{~mL}$, aggregation of bulk silver nanoparticles and its quasi spherical morphology observed Figs. 7a and b. Grain shape were transformed in to 
hexagonal Fig. 7c and rectangular nanosheet packaging Fig. $7 d$. Therefore, the shape and aggregation depend upon the extract concentration. It was observed that the extract concentration of $10 \mathrm{~mL}$ was insufficient to avoid the agglomeration. In such a little quantity of extract concentration, silver atoms cannot form co-ordination bonds with biomolecules. Thus, they coalesce with each other and form large agglomeration. However, with increase in extract concentration from $30 \mathrm{~mL}$ to $40 \mathrm{~mL}$ additional agglomeration were created, but it has no significant effect on the particle size distribution. $20 \mathrm{~mL}$ of extract concentration leads to the formation of well dispersed silver nanoparticles.

\subsection{Dynamic Light Scattering Analysis}

Dynamic light scattering (DLS) is a technique used to determine the size, size distribution profile and polydispersity index of particles in a colloidal suspension undergoing Brownian motion. Fig. 8 shows the DLS graph of Ag-NPs of T. procumbens. It was observed that the size distribution Ag-NPs ranged from $10.8 \mathrm{~nm}-46.5 \mathrm{~nm}$. The extensive spectrum of size analyzer confirms that the particle size decreased when compared with XRD results. Among the four the high intensity peak is observed for $20 \mathrm{~mL}$ of plant concentration with small particle size (10.8 $\mathrm{nm})$.
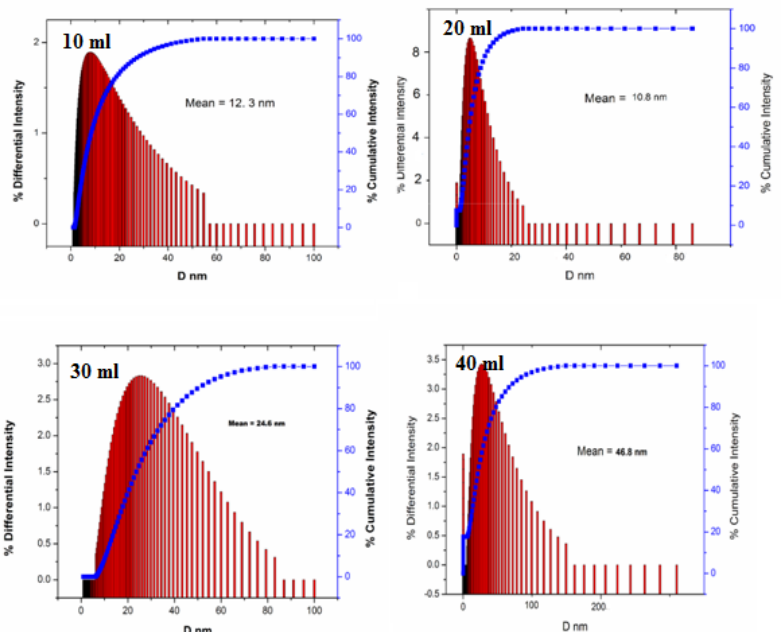

Fig. 8 Size distribution of Ag-NPs at different concentration of T. procumbens plant extract

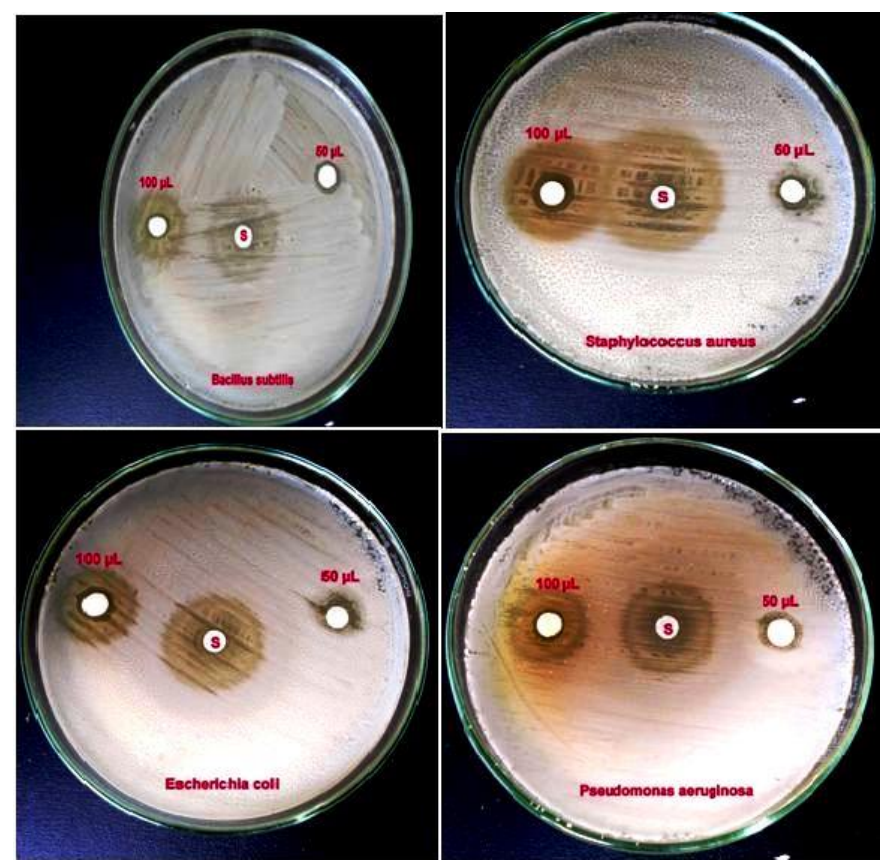

Fig. 9 Anti bacterial efficacy of Ag-NPs synthesized by $20 \mathrm{~mL}$ of extract concentration for different bacterial strains

\subsection{In-vitro Antibacterial Evaluation}

Antibacterial properties can be used to prevent and reduce the bacteria colonization. The synthesized Ag-NPs were screened for the antibacterial efficacy against two gram-positive bacteria viz., Bacillus subtilis and Staphylococcus aureus and two gram-negative bacteria viz., Escherichia https://doi.org/10.30799/jnst.207.19050114 coli, Pseudomonas aeruginosa via disc diffusion method. Ciprofloxacin was used as reference standard for comparing the results.

The nanoparticles release silver ions in the bacterial cells, which enhance their bactericidal activity. It is possible that the amino groups enhance the ionic exchange of $\mathrm{Ag}^{+} / \mathrm{H}^{+}$ions. In this study, we determine the antibacterial efficacy of synthesized Ag-NPs with different concentration of plant extract ( $10 \mathrm{~mL}$ to $40 \mathrm{~mL}$ ). Antimicrobial activity of Ag-NPs was studied against 4 different human pathogens. The effect of different concentration i.e. $50 \mu \mathrm{g} / \mathrm{mL}$ and $100 \mu \mathrm{g} / \mathrm{mL}$ of Ag-NPs against gram positive and gram-negative bacterial strains were reported in Fig. 9 and Table 3

Smaller particles having larger surface area for interaction would have efficient bacterial effect than larger particles. Maximum antibacterial activity was shown by Ag-NP extract with inhibition zone minimum of 20 $\mathrm{mm}$ (at Ag-NPs concentration of $100 \mu \mathrm{g} / \mathrm{mL}$ ) against Staphylococcus aureus. The most strains of $S$. aureus were damaged and extensively disappeared by addition of Ag-NPs.

Table 3 Zone of inhibition of silver nanoparticles at different concentrations for different bacterial cultures

\begin{tabular}{lllll}
\hline S. & Name of the Organisms & \multicolumn{3}{l}{ Zone of inhibition $(\mathrm{mm})$} \\
No & & Standard* & $50 \mu \mathrm{L}$ & $100 \mu \mathrm{L}$ \\
\hline 1 & Bacillus subtilis & 21 & 08 & 19 \\
2 & Staphylococcus aureus & 23 & 12 & 20 \\
3 & Escherichia coli & 20 & 10 & 16 \\
4 & Pseudomonas aeruginosa & 20 & 12 & 15 \\
\hline
\end{tabular}

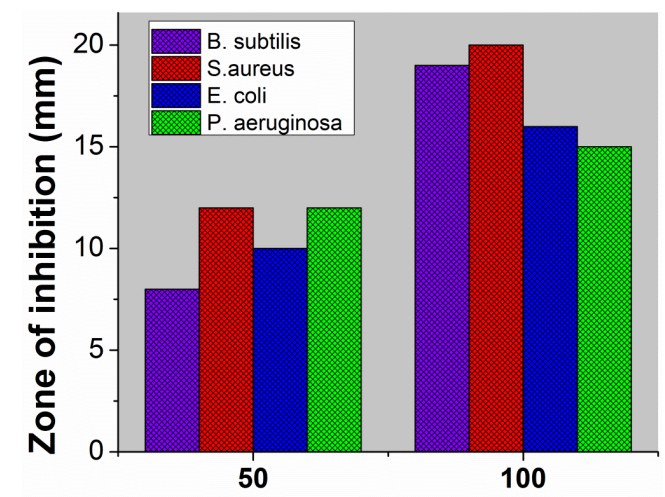

Concentration $(\mu \mathrm{l})$

Fig. 10 Comparison of the inhibition zone with different concentration for various bacterial pathogens

\section{Conclusion}

Silver nanoparticles were synthesized using medicinal herb $T$. procumbens plant extract, which provides facile, efficient and was suitable to large scale synthesis of Ag-NPs. The formation of well-defined dimensions of silver nanoparticles have been estimated and optimized by XRD. FTIR analysis of plant extract and nanoparticles samples indicated the involvement of hydroxyl, amino, carbonyl and amide moieties in the formation and stabilization of the developed nanoparticles. SEM techniques showed that the morphological transformation of the Ag-NPs strongly depend on the extract quantity. Ag-NPs sample of the smaller size and narrow size distribution was obtained by reacting $20 \mathrm{~mL}$ of $T$. procumbens plant extract. Strong anti-bactericidal activity is observed against gram ( + ) and gram (-) bacterial strains of Ag-NPs to be used as antimicrobial agent in therapeutic as well as food and cosmetic industries. The findings will therefore pave technique for biogenic process to suggest large scale creation of benign Ag-NPs which directly will simplify their extensive applications rapidly.

\section{References}

[1] D. Devina Merin, S. Prakash, B. Valentine Bhimba, Antibacterial screening of silver nanoparticles synthesized by marine micro algae, Asian Pacific J. Trop. Med. 3 (2010) 797-799.

[2] Mambo Moyo, Makore Gomba, Tichaona Nharingo, Afzelia quanzensis bark extract for green synthesis of silver nanoparticles and study of their antibacterial activity, Int. J. Ind. Chem. 6 (2015) 329-338.

[3] A. Sneha Mohan, S. Oluwatobi, B. Oluwafemi, C. Soney, C. George, et.al., Completely green synthesis of dextrose reduced silver nanoparticles, its antimicrobial and sensing properties, Carbohyd. Polym. 106 (2014) 469-474.

[4] K. Virender Sharma, A. Ria, Yngard, Y. Lin, Silver nanoparticles: green synthesis and their antimicrobial activities, Adv. Col. Int. Sci. 145 (2009) 83-96. 
[5] S.R. Tetgure, A.U. Borse, B.R. Sankapal, et al., Green biochemistry approach for synthesis of silver and gold nanoparticles using Ficus racemosa latex and their pH-dependent binding study with different amino acids using UV/Vis absorption spectroscopy, Amino Acids 47 (2015) 747-756.

[6] R. Sangeetha, Pavithra Niranjan, N. Dhanalakshmi, Characterization of silver nanoparticles synthesized using the extract of the leaves of Tridax procumbens, Res. J. Med. Plants 10 (2016) 159-166.

[7] C. Ramteke, T. Chakrabarti, B. Ketan Sarangi, R. Avatar Pandey, Synthesis of silver nanoparticles from the aqueous extract of leaves of Ocimum sanctum for enhanced antibacterial activity, Jour. Chem. 4 (2013) 1-7.

[8] Susan Azizi, Farideh Namvar, Mahnaz Mahdavi, Mansor Bin Ahmad, Rosfarizan Mohamad, Biosynthesis of silver nanoparticles using brown marine macroalga, Sargassum muticum aqueous extract, Materials 6 (2013) 5942-5950.

[9] N. Matinise, X.G. Fuku, K. Kaviyarasu, N. Mayedwa, M. Maaza, ZnO nanoparticles via Moringa oleifera green synthesis: Physical properties \& mechanism of formation, Appl. Surf. Sci. 406 (2017) 339-347.

[10] K. Anandalakshmi, J. Venugobal, V. Ramasamy, Characterization of silver nanoparticles by green synthesis method using Pedalium murex leaf extract and their antibacterial activity, Appl. Nanosci. 6 (2016) 399-408.

[11] J.E. Morvin Yabesh, S. Prabhu, S. Vijayakumar, An ethnobotanical study of medicinal plants used by traditional healers in silent valley of Kerala, India, Jour. Ethnopharm. 3 (2014) 774-789.

[12] O.N. Erick, M. Nalini Padmanabhan, Antimicrobial activity of biogenic silver nanoparticles synthesized using Tridax procumbens L., Int. J. Curr. Res. Aca. Rev. 2 (2014) $32-40$

[13] T. Dhanalakshmi, S. Rajendran, Synthesis of silver nanoparticles using Tridax procumbens and its antimicrobial activity, Arch. Appl. Sci. Res. 4 (2012) 12891293.

[14] H.B. Kushwaha, C.P. Malik, Biosynthesis of silver nanoparticles using fresh extracts of Tridax procumbens Linn, Ind. Jour. Exp. Biol. 52 (2014) 359-368.

[15] R.S. Policegoudra, P. Chattopadhyay, S.M. Aradhya, R. Shivaswamy, L. Singh, V. Veer, Inhibitory effect of Tridax procumbens against human skin pathogens, J. Herbal. Med. 4 (2014) 83-88.

[16] D.A. Bhagwat, S.G. Killedar, R.S. Adnaik, Antidiabetic activity of leaf extract of Tridax procumbens, Int. J. Green. Pharm. 2 (2008) 126-128.
[17] C. Ikewuchi Jude, C. Ikewuchi Catherine, M. Igboh Ngoz, Chemical profile of Tridax procumbens Linn, Pak. Jour. Nutr. 8 (2009) 548-550.

[18] M. Jannathul Firdhouse, P. Lalitha, Biosynthesis of silver nanoparticles using the extract of Alternanthera sessilis - antiproliferative effect against prostate cancer cells, Cancer Nano 4 (2013) 137-143.

[19] P. Logeswari, S. Silambarasan, J. Abraham, Ecofriendly synthesis of silver nanoparticles from commercially available plant powders and their antibacterial properties, Sci. Iranica. 20 (2013) 1049-1054.

[20] Kamyar Shameli, Mansor Bin Ahmad, Seyed Davoud Jazayeri, Parvaneh Shabanzadeh, et al., Investigation of antibacterial properties silver nanoparticles prepared via green method, Chem. Cent. J 6 (2012) 73-82.

[21] M. Rai, A. Yadav, A. Gade, Silver Nanoparticles as a new generation of antimicrobials, Biotech. Adv. 27 (2009) 76-83.

[22] M. Bin Ahmad, J. Jye Lim, K. Shameli, N. Azowa Ibrahim, M. Y. Tay, B.W. Chieng, Antibacterial activity of silver bionanocomposites synthesized by chemical reduction route, Chem. Central Jour. 6 (2012) 101-109.

[23] Y. Murali Mohan, K. Vimala, V. Thomas, K. Varaprasad, B. Sreedhar, et al., Controlling of silver nanoparticles structure by hydrogel networks, J. Colloid. Interf. Sci. 342 (2010) 73-82.

[24] S. Amrut, Lanje, J. Satish, Sharma, B. Ramchandra, Pode, Synthesis of silver nanoparticles: a safer alternative to conventional antimicrobial and antibacterial agents, J. Chem. Pharm. Res. 2(3) (2010) 478-483.

[25] M. Abdul Majeed Khan, S. Kumar, M. Ahamed, S.A. Alrokayan, M. Saleh AlSalhi, M. Khan, Structural and thermal studies of silver nanoparticles and electrical transport study of their thin films, Nano. Res. Lett. 6 (2011) 434-441.

[26] J. Prince Richard, I. Kartharinal Punithavathy, S. Johnson Jeyakumar, M. Jothibas, P. Praveen, Effect of morphology in the photocatalytic degradation of methylviolet dye using ZnO nanorods, J. Mater Sci. Mater Electron. 28 (2016) 4025-4034.

[27] Y.P. Venkata Subbaiah, P. Prathap, K.T. Ramakrishna Reddy, Structural, electrical and optical properties of $\mathrm{ZnS}$ films deposited by close-spaced evaporation, Appl. Surf. Sci. 253 (2006) 2409-2415.

[28] B.K. Jena, B.K. Mishra, S. Bohidar, Synthesis of branched Ag nanoflowers based on a bioinspired technique: their surface enhanced Raman scattering and antibacterial activity, J. Phys. Chem. 113 (2009) 14753-14758. 